\title{
THE EXAMINATION OF OPERATIONAL LEASING IN TERM OF TURKISH ACCOUNTING REGULATIONS
}

\author{
DOI: 10.17261/Pressacademia.2020.1243 \\ PAP- V.11-2020(15)-p.73-78
}

Ugur Kaya ${ }^{1}$, Oguz Yusuf Atase ${ }^{2}$, Yasar Bayraktar ${ }^{3}$

${ }^{1}$ Karadeniz Technical University, Department of Business, Trabzon, Turkey. ukaya105@yahoo.com, ORCID: 0000-0003-1358-7122

${ }^{2}$ Karadeniz Technical University, Department of Business, Trabzon, Turkey. oguzatasel@hotmail.com, ORCID: 0000-0003-1654-9850

${ }^{3}$ Karadeniz Technical University, Department of Business, Trabzon, Turkey. ysr bayraktar@hotmail.com, ORCID: 0000-0002-6974-5292

\section{To cite this document}

Kaya, U., Atasel, O. Y. ve Bayraktar, Y. (2020). The examination of operational leasing in term of Turkish accounting regulations. PressAcademia Procedia (PAP), V.11, p.73-78

Permanent link to this document: http://doi.org/10.17261/Pressacademia.2020.1243

Copyright: Published by PressAcademia and limited licensed re-use rights only.

\begin{abstract}
Purpose- The purpose of this study is to explain the accounting principles for the issues that are special in operating leasing transactions in the framework of Tax Procedure Law, General Communique on Accounting System Application, Turkish Accounting and Financial Reporting Standards and the Financial Reporting Standard for Large and Medium-Sized Businesses.

Methodology- Accounting of operating leasing transactions will be handled within the framework of existing accounting regulations. Thus, similarities and differences in the accounting of these transactions will be revealed.

Findings- In TFRS 16, which was put into practice instead of TAS 17, it was stated that the right of use should be shown in assets and the lease obligations should be shown in liabilities without discriminating financial or operational leases for the lessee. In terms of the leaser, the classification of operations and financial leases continued, as in TAS 17. In TAS 17 and SME FRS Chapter 15, the distinction between operational and financial lease remains valid for the lessee and the lessor. It has been determined that only provisions regarding financial leasing are included in VUK, and accounts that will be used only for leasing transactions are included in MSUGT.

Conclusion- Prediction of a uniform rental model for lessee businesses within the scope of TFRS 16, it is expected that these types of businesses will have significant impacts on ensuring the fair presentation of their assets and liabilities and increasing the comparability of financial statements.
\end{abstract}

Keywords: TFRS 16, TAS 17, SME FRS Chapter 15, leasing transactions, operating leases.

JEL Codes: M41, M48, M49

\section{FAALIYET KIRALAMASININTÜRKIYE’DEKI MUHASEBE DÜZENLEMELERI AÇISINDAN INCELENMESi}

\section{ÖZET}

Amaç- Bu çalışmanın amacı, faaliyet kiralaması işlemlerinde özellik arz eden hususların Vergi Usul Kanunu, Muhasebe Sistemi Uygulama Genel Tebliği, Türkiye Muhasebe ve Finansal Raporlama Standartları ve Büyük ve Orta Boy İşletmeler için Finansal Raporlama Standard çerçevesinde muhasebeleştirilme esaslarını açıklamaktır.

Yöntem- Faaliyet kiralaması işlemlerinin muhasebeleştirilmesi hususu mevcut muhasebe düzenlemeleri çerçevesinde ele alınacaktır. Böylece faaliyet kiralaması işlemlerinin muhasebeleştirilmesindeki benzerlik ve farklılıklar ortaya konacaktır.

Bulgular- TMS 17 yerine uygulamaya konulan TFRS 16' da, kiracı açısından finansal ya da faaliyet kiralaması ayrımı yapılmayarak doğrudan kullanım hakkının varlıklarda, kira borçlarının ise yükümlülükte gösterilmesi gerektiği belirtilmiştir. Kiraya veren açısından ise TMS 17'de olduğu gibi faaliyet ve finansal kiralama sınıflandırılmasına devam edilmiştir. TMS 17 ve BOBi FRS Bölüm 15'de kiracı ve kiraya veren açısından faaliyet ve finansal kiralama ayrımı geçerliliğini korumaktadır. VUK'da sadece finansal kiralama ile ilgili hükümle re yer verildiği, MSUGT'da ise sadece kiralama işlemleri hususunda kullanılacak hesapların yer verilerek açılklandığı tespit edilmiştir.

Sonuç- TFRS 16 kapsamında kiracı işletmeler açısından tek tip kiralama modelinin öngörülmesi, bu tür işletmelerin varlık ve yükümlülüklerinin gerçeğe uygun sunumunun sağlanmasına ve finansal tabloların karşılaştırılabilirliğinin artırılmasına önemli etkileri olması beklenmektedir.

Anahtar Kelimeler: TFRS 16, TMS 17, BOBi FRS Bölüm 15, kiralama işlemleri, faaliyet kiralaması. JEL Kodlar: M41, M48, M49 


\section{Gíriş}

İşletmeler hem yatırım hem de faaliyet sürecinde kullanacağı varlıkları satın alarak, inşa ederek veya üreterek elde edebilir. Bu edinim ise özsermaye veya yabancı sermaye kullanılarak gerçekleştirebileceği gibi kiralama yoluyla da yapabilmektedir. İşletmeler genellikle sabit varlıklara yaplacak yatırımlarda özsermaye ya da yabancı sermaye maliyetinden önemli ölçüde kurtulabilmek için kiralama yolunu tercih etmektedir (Akdoğan, Aktaş, Deran, Erhan ve Acar, 2011, s.63). İngilizce "leasing" kelimesinin çevirisi olan kiralama, ekonomik ömre sahip bir varlığın kira ödemeleri karşılığında kullanım hakkının üçüncü kişilere devredilmesini ifa de etmektedir (Sipahi, 2004, s.3; Öztaş ve Burak, 2014, s.52). Kiralamalar temel olarak "finansal kiralama" ve "faaliyet kiralaması" olmak üzere iki türe ayrılabilir (Gökgöz, 2019, s.319). Finansal kiralama, dayanak varlığın mülkiyetinden kaynaklanan tüm risk ve getirilerin önemli ölçüde devredildiği kiralamadır. Faaliyet kiralaması ise, dayanak varlığın mülkiyetinden kaynaklanan tüm risk ve getirilerin önemli ölçüde devredilmediği kiralamadır (TFRS 16, EKA).

Kiralama işlemlerinin muhasebeleştirilmesi ve finansal raporlarda sunulabilmesi için uluslararası ve ulusal bir takım düzenlemeler yapılmıştır. Uluslararası alanda ilk olarak Uluslararası Muhasebe Standartları Kurulu (International Acconting Standards Board-IASB) tarafından Uluslararası Muhasebe Standardı (UMS) 17 Kiralama İşlemleri Standardı yayınlamıştır. Ancak söz konusu standartta, faaliyet kiralaması işlemlerinde kiralamaya konu varlık ve yükümlülüğün bilanço dışı bırakılması öngörüldüğünden, finansal tablo kullanıcılarına bu konuda şeffaf bir sunum gerçekleştirilemediği için ilgili standart eleştiri konusu yapılmaktadır (Akdoğan ve Doğan, 2020, s.166-169; Akdoğan, 2019, s.80). Zira UMS 17' de kiralama işlemleri tüm taraflar için faaliyet ve finansal kiralama olarak ayrıma tabi tutulmakta ve bunlara ilişkin muhasebeleştirme hükümleri farklılaşmaktaydı. Kiracı açısından faaliyet kiralamalarının tamamen bilanço dışında kalması, diğer bir ifadeyle kiralama işlemlerine ilişkin varlık ve yükümlülüklerin finansal durum tablosuna yansıtılmaması, özellikle karşılaştırmalı analizler açısından büyük sorun teşkil etmekteydi. Finansal kiralamayla uzun süreli kiralama yapanlar ile kısa süreli ama devamlı kiralama yapanların finansal tablolarının karşılaştırılabilirlikleri azaltmaktaydı. Ayrıca, faaliyet kiralaması nedeniyle, bazı işletmelerin mali durumları tam ve doğru bir şekilde sunulamamaktaydı. Özellikle bu durum havayolu başta olmak üzere taşıma, enerji, telekomünikasyon ve perakende vb. sektörlerde gerçeğe uygun olmayan sunum sorunlarına neden olmaktaydı (Örten, Kaval ve Karapınar, 2019, s.283).

UMS 17' nin yukarıda sözü edilen eksikliklerinden dolayı Uluslararası Muhasebe Standartları Kurulu (IASB) ve Amerikan Finansal Muhasebe Standartları Kurulu (Financial Accounting Standards Board-FASB), kiralama işlemleri ile ilgili standardın yeniden düzenlenmesine yönelik çalışmalara başlamıştır (Aslan, 2018, s.57; Marşap ve Yanık, 2018, s.24). Bu bağlamda IASB ve FASB yaşanan gelişmeler doğ rultusunda kiralama işlemleri ile ilgili eleştirileri dikkate alarak uluslararası uyumlaştırma uygulamalarının bir parçası olarak 2006 y ılında ortak bir proje başlatmıştır (Marşap ve Yanık, 2018, s.24). Nitekim bu projenin sonucunda FASB, 2016 yılında ASC 842 Kiralama Standardını, IASB ise 2019 yııından itibaren UMS 17 standardının yerini alan UFRS 16 Kiralama İşlemleri Standardını uygulamaya geçirmiştir (Öztürk, 2016, s.3).

Türkiye'de ise kiralama işlemleri ile ilgili 2005 yılında UMS 17'nin birebir çevirisi olan Türkiye Muhasebe Standardı (TMS) 17 Kiralama İşlemleri Standardı yayınlanmıştır. Kamu Gözetimi Muhasebe ve Denetim Standartları Kurumu (KGK) dünyadaki gelişmelerin paralelinde 2017 yılında UFRS 16' nin birebir çevirisi olan Türkiye Finansal Raporlama Standardı (TFRS) 16 Kiralamalar Standardını taslak metin halinde yayımlayarak kamuoyu görüşüne sunmuştur (Akbulut, 2018, s.18). Bu standart 31.12.2018 tarihinden sonra başlayan hesap dönemlerinde uygulanmak üzere 16.04.2018 tarihli ve 29826 sayılı Resmi Gazete' de yayımlanarak yürürlüğe girmiştir. Kiralama işlemleri ile ilgili bir diğer düzenleme ise yine KGK tarafından yayınlanan bağımsız denetime tabi olup TMS/TFRS'yi uygulamayan işletmelerin uygulamada zorunlu oldukları Büyük ve Orta Boy İşletmeler için Finansal Raporlama Standardı (BOBI FRS) kapsamında yer verilmiştir. BOBi FRS'nin 15. Bölümü sadece kiralama işlemlerine ilişkin hükümleri içermektedir. Son olarak Muhasebe Sistemleri Uygulama Genel Tebliği (MSUGT) ile Vergi Usul Kanunu'nda kiralama işlemleri ile ilgili hükümlere yer verildiği söylenebilir.

Türkiye' deki finansal raporlama çerçeveleri açısından kiralama işlemleri kapsamında; TFRS 16 ile ilgili (Aslan, 2018; Marşap ve Yanık, 2018), TMS 17 ile ilgili (Şeker ve Çemberlitaş, 2018; Pamukçu ve Çakmak, 2017), VUK ile ilgili (Şentürk, 2016), TMS 17 ile VUK' un birlikte ele alındığı (Cengiz, 2017; Gönen ve Akça, 2014), TMS 17 ile TFRS 16’nın birlikte ele alındığı (Gökgöz, 2019; Aksoy Hazır, 2018), TMS 17, TFRS 16 ve VUK' un birlikte ele alındığı (Doğan, 2019), TFRS 16, BOBi FRS ve VUK' un birlikte ele alındığı (Yalçın, 2019) ve son olarak TMS 17, TFRS 16, BOBi FRS ve VUK' un birlikte ele alındığı (Demirci ve Kıymaz Kıvraklar, 2018) çalışmalar yapılmıştır. Ancak bu çalışmalar içerisinde faaliyet kiralamasına TFRS 16, TMS 17, BOBi FRS ve VUK kapsamında çok az yer verilmekle birlikte, ağırlıklı olarak finansal kiralama işlemleri üzerinde durulmuştur. Bu çalışmada literatürden farklı olarak faaliyet kiralaması ile ilgili Türkiye' deki mevcut düzenlemeler karşılaştırılarak benzerlik ve farklılıklar ortaya konacaktır. Ayrıca faaliyet kiralaması işlemlerinin varsayımsal bir örnek uygulama aracılığıyla TFRS 16, TMS 17, BOBI FRS, MSUGT ve VUK doğrultusunda muhasebeleştirilme hususuna ve finansal tablolara yansımasına yönelik açılamalar yapılacaktır. Çalışmanın bu yönüyle literatüre katkı sağlaması beklenmektedir.

\section{DÜZENLEMELERIN KARŞILAŞTIRMALI OLARAK DEĞERLENDIRILMESi}

Çalışmanın esas konusunu teşkil eden faaliyet kiralaması ile ilgili bulgular TMS/TFRS, BOBi FRS, MSUGT ve VUK açısından ayrı başlıklar halinde açıklanarak düzenlemelerin karşılaştırılmasına yer verilecektir.

TMS/TFRS; TMS 17, 2019 yılı itibariyle yerini TFRS 16 Kiralama Standardına bırakmış olup, TMS 17' de kiracı ve kiraya veren açısından finansal ve faaliyet kirlaması ayrımı söz konusudur. TFRS $16^{\prime}$ da ise, kiracı açısından finansal veya faaliyet kiralaması ayrımı yapılmaksızın doğrudan kullanım hakkının varlık, kira borçlarının ise yükümlülük olarak gösterilmesi gerektiği belirtilmiştir. Kiraya veren açısından ise TMS $17^{\prime}$ de olduğu gibi faaliyet ve finansal kiralama sınıflandırılması TFRS 16' da da devam etmektedir. TFRS 16'da kısa vadeli kiralamalar ile dayanak varlığın düşük değerli olduğu kiralamalar konusunda bir takım istisnalara yer verilmiştir. Bu iki konu kapsamında kiracı, isterse bu kiralamalarla ilişkili kira ödemelerini, kiralama süresi boyunca doğrusal ya da başka bir sistematik esasa göre gider olarak finansal tablolara yansıtabilmektedir. 
BOBi FRS; BOBi FRS'nin Kiralamalar Bölüm 15'te faaliyet kiralaması yerine geleneksel kiralama adı kullanılmış olup, TMS 17' deki gibi kiracı açısından kiralama işlemleri faaliyet ya da finansal kiralama şeklinde sınıflandırılmıştır. Bir başka ifadeyle faaliyet kiralamasının bilanço dışı bırakılmasına devam edilmektedir.

MSUGT ve VUK; 213 sayılı VUK' un mükerrer 290. maddesi ile VUK'un 319 Sıra No'lu Tebliği, kiralama işlemlerinden doğan hak, borç ve alacakların değerlemesi ve amortisman uygulamalarını içermektedir. Ancak bu kiralama işlemleri tamamen finansal kiralama ile ilgili olup, faaliyet kiralaması ile ilgili doğrudan bir hükme rastlanmamıştır. 11 Sıra No'lu MSUGT'de ise, kiralama işlemleri hususunda kullanılacak hesaplara yer verilmiştir. Faaliyet kiralaması ile ilgili herhangi bir hükme rastlanmamıştır.

\subsection{Türkiye'deki Mevcut Düzenlemelerdeki Hükümlerin Değerlendirilmesi}

Bu başık altında TMS/TFRS, BOBI FRS, VUK ve MSUGT düzenlemeleri tanım, kapsam ve kiralama işlemlerinin sınıflandırılması bakımından karşılaştırmalı olarak ele alınmıştır.

Tanım açısından karşılaştırma; kiralama konusu varlık TFRS 16'da "varlığın kullanımını kontrol etme hakkı" olarak, TMS 17 ve BOBI FRS Bölüm 15 'te "varlığın kullanım hakkı" olarak VUK' da ise "varlığın mülkiyetinden kaynaklanan tüm risk ile yararlarının devredilmesi" şeklinde yer almaktadır.

Kapsam açısından karşılaştırma; TFRS 16'nın en net kapsama sahip olduğu ifade edilebilir. Bu düzenlemeyi sırasıyla TMS 17, BOBi FRS Bölüm 15 ve VUK izlemektedir. Bir diğer önemli husus, TMS 17 kapsamında kiracı ve kiraya veren a çısından faaliyet kiralamasına giren yatıı ım amaçlı gayrimenkullerin TMS 40 Yatııı Amaçlı Gayri Menkuller Standardı́na göre değerlendirilmesi TFRS 16'da sonlandırılmıştır. Diğer bir ifadeyle bu tür kiralamalar da TFRS 16 kapsamına girmektedir.

Kiralama işlemlerinin sınıflandırılması bakımından karşılaştırma; TFRS 16'da kiracı açısından faaliyet kiralaması ve finansal kiralama ayrımına son verilerek tüm kiralamalar finansal kiralama olarak değerlendirilmiştir. Kiralamayla ilgili varlıkların "Kullanım Hakkı Varlığı" olarak sınıflandırılmasına ve yükümlülükler ile birlikte finansal durum tablosunda gösterilmesine yer verilmiştir. Kiraya ver en açısından ise TMS 17 ve TFRS 16 uyumluluk göstermekte olup, faaliyet ve finansal kiralama ayrımına devam edilmektedir. TMS 17 ve BOBi FRS Bölüm 15 hem kiracı hem de kiraya veren açısından uyumluluk göstermektedir. Sadece BOBi FRS Bölüm 15'de faaliyet kiralaması yerine geleneksel kiralama adı kullanılmaktadır. VUK' da ise doğrudan finansal kiralama ile ilgili hükümler bulunmaktadır.

Yapılan açıklamalar doğrultusunda TFRS $16^{\prime}$ ıın en temel düzenlemesinin, faaliyet kiralama işlemlerinin finansal durum tablosuna dâhil edilmesi hususu olduğu söylenebilir. Bu düzenleme ile faaliyet kiralamasına konu olan varlıklar bilançoda, duran varlıklar hesap sınıfında, maddi duran varlıklar veya maddi olmayan duran varlıklar hesap grubunda "Kullanım Hakkı Olan Varlıklar" olarak, faaliyet kiralaması borçları ise, borçlardan ayrı bir başlık olarak ya da borçlar içinde "Kiralama Borçları" olarak raporlanmaktadır. Faaliyet kiralamasına konu olan varlığa ilişkin amortisman gideri ve faiz gideri gelir tablosunda raporlanacaktır. Standarda göre, kira borçlarına ait ödemeler, nakit akış tablosunda, finansal faaliyetlerden doğan nakit akışı grubu içinde izlenecektir. Değişken kira ödemeleri ve kısa vadeli kiralama borçları ise nakit akış tablosunda işletme faaliyetlerinden nakit akışları bölümünde gösterilmelidir (Aslan, 2018, s.63). Atfedilen “Kullanım Hakkı Olan Varlıklar" KGK tarafından yayınlanan TMS/TFRS uyumlu Hesap Planı Taslağı'nda ve MSUGT Tekdüzen Hesap Planı'nda hangi hesap grubu ve hangi hesap adı altında yer alacağı açık değildir. Ancak KGK tarafından yayınlanan "Finansal Tablo Örnekleri ve Kullanım Rehberi”nde kiracıların kullanım hakkı varlıklarını finansal durum tablosunda ya da dipnotlarında diğer varlıklarından ayrı bir şekilde g östermeyi tercih etmesi halinde bu varlıklarını "Kullanım Hakkı Varlıkları" kalemi altında göstermesi gerektiği belirtilmiştir. Kullanım hakkı varlıklarını finansal durum tablosunda ayrı bir şekilde göstermeyi tercih etmeyen kiracı işletmeler için ise, kullanım hakkı varlıklarını, ilişkili olduğu dayanak varlıklar altında finansal durum tablosuna yansıtıp gerekli açıklamalara dipnotlarda yer vermesi gerektiği ifade edilmektedir.

\section{TFRS 16, TMS 17, BOBi FRS BÖLÜM 15, VUKVE MSUGT KAPSAMINDA FAALIYET Kİ RALAMASI İL I LGi Li ÖRNEK UYGULAMA}

Bu kısımda daha önce yer verilen açıklamalar doğrultusunda kiracı açısından faaliyet kiralaması ile ilgili örnek uygulamaya verilerek düzenlemeler arasındaki farklııklar ortaya konmaya çalışılmıştır.

Örnek Uygulama: Emir İşletmesi, 01.01.2019 tarihinde A AVM'sinden satış ve pazarlama faaliyetlerinde kullanmak üzere 5 yıllığına bir mağaza kiralamıştır. Kiralama faaliyet kiralaması şeklinde olup, piyasa faiz oranı \% 10 ve yıllık 30.000,-TL eşit tutarla ödeme yapılmas hususunda anlaşılmıştır. Kiralamanın toplam borcu 150.000,-TL'dir. (Doğrusal amortisman yöntemi kullanılacaktır.)

TFRS 16'ya göre çözüm: Öncelikle kiralama borcunun bugünkü değeri hesaplanarak kullanım hakkı ve kira yükümlülüğünün finansal durum tablosuna yansıtılması gerekmektedir. Buna göre; Bugünkü Değer $(B D)=A \times((1+i) n-1) /((1+i) n \times i))=30.000,-T L \times 3,79^{1}=113.724,-T L^{2}$ olarak hesaplanır. Daha sonra yıllara göre ayrılması gereken amortisman tutarı hesaplanır.

Doğrusal amortisman yöntemi olduğundan yıllar itibariyle ayrılacak amortisman tutarı 22.745, -TL ${ }^{3}$ (113.724,-TL/5yıl) olarak hesaplanır. Yıllar itibariyle ayrılacak amortisman tutarı hesaplandıktan sonra yıllık olarak ödenecek kira tutarından ana para ve faizin ayrıştırılması gerekmektedir. Buna göre ilgili hesaplama Tablo 1'de gösterilmektedir.

\footnotetext{
$1((1+i) n-1) /((1+i) n \times i))=((1+0,10) 5-1) /((1+0,10) 5 \times 0,10)=3,790786769$ şeklinde hesaplanmaktadır

2 3,790786769 x 30.000,-TL= 113.723,60 TL şeklinde hesaplanarak 113.724,-TL'ye yuvarlanmıştır.

3 113.724, -TL/5yıl=22.744,80 TL/yıl şeklinde hesaplanarak 22.745,-TL'ye yuvarlanmıştır.
} 
Tablo 1: Faaliyet Kiralamasına Ait Ödeme Planı

\begin{tabular}{|l|l|l|l|l|l|l|}
\hline & $\mathbf{2 0 1 9}$ & $\mathbf{2 0 2 0}$ & $\mathbf{2 0 2 1}$ & $\mathbf{2 0 2 2}$ & $\mathbf{2 0 2 3}$ & Toplam \\
\hline Kira Ödemeleri & $30.000,-$ & $30.000,-$ & $30.000,-$ & $30.000,-$ & $30.000,-$ & $150.000,-$ \\
\hline Kira Ödemelerinin Bugünkü Değeri & $27.273,-$ & $24.793,-$ & $22.539,-$ & $20.490,-$ & $18.628,-$ & $113.724,-$ \\
\hline Faaliyet Kiralaması Borcu & $113.724,-$ & $95.096,-$ & $74.606,-$ & $52.066,-$ & $27.273,-$ & \\
\hline Kullanım Hakkı Varlığı (Net) & $113.724,-$ & $90.979,-$ & $68.234,-$ & $45.489,-$ & $22.745,-$ & \\
\hline Faiz Gideri & $11.372,-$ & $9.510,-$ & $7.461,-$ & $5.207,-$ & $2.727,-$ & $36.276,-$ \\
\hline Anapara ödemesi & $18.628,-$ & $20.490,-$ & $22.539,-$ & $24.793,-$ & $27.273,-$ & $113.724,-$ \\
\hline Amortisman Gideri & $22.745,-$ & $22.745,-$ & $22.745,-$ & $22.745,-$ & $22.745,-$ & $113.724,-$ \\
\hline
\end{tabular}

TMS 17, ВОВі FRS Bölüm 15 ve VUK'a göre çözüm: Bu üç düzenlemede de kiracı açısından faaliyet ve finansal kiralama ayrımı söz konusudur. BOBi FRS Bölüm 15 de faaliyet kiralaması yerine geleneksel kiralama adı kullanıldığı daha önce belirtilmişti. Örnek uygulamadaki faaliyet kiralamasının yılık 30.000,-TL'lik tutarı faaliyet giderleri içerisinde raporlanacaktır. Bundan dolayı bu düzenlemeler kapsamında faaliyet kiralaması ile ilgili ödemeler doğrudan kar veya zarar tablosuna yansıtılmakta, finansal durum tablosuyla ilişkilendirilmemektedir. Ayrıca faaliyet kiralaması ile ilgili açıklamalar da dipnotlar aracılığıyla sunulmaktadır. Tablo 2'de faaliyet kiralamasının finansal tablolara yansıtılması ilgili kalemler sunulmaya çalışılmıştır (Yalçın, 2019, s.1636).

Tablo 2: Faaliyet Kiralamasının Finansal Tablolara Yansıması

\begin{tabular}{|c|c|c|c|c|c|c|c|c|}
\hline & \multicolumn{3}{|c|}{ Finansal Durum Tablosu } & \multicolumn{4}{|c|}{ Kapsamlı Gelir Tablosu } \\
\hline & & Net Varlık Fazlası & Borç Fazlası & Özsermaye Farkı & Amortisman Gideri & Faiz Gideri & Kira Gideri & Net Kar \\
\hline \multirow[b]{2}{*}{2019} & TFRS 16 & $90.979,-$ & $95.096,-$ & $-4.117,-$ & $22.745,-$ & $11.372,-$ & & $-4.117,-$ \\
\hline & $\begin{array}{l}\text { TMS 17, BOBi FRS, } \\
\text { VUK }\end{array}$ & & & $0,-$ & & & 30.000,- & \\
\hline \multirow[b]{2}{*}{2020} & TFRS 16 & $68.234,-$ & $74.606,-$ & $-6.371,-$ & $22.745,-$ & $9.510,-$ & & $-2.254,-$ \\
\hline & $\begin{array}{l}\text { TMS 17, BOBi FRS, } \\
\text { VUK }\end{array}$ & & & $0,-$ & & & $30.000,-$ & \\
\hline \multirow[b]{2}{*}{2021} & TFRS 16 & $45.489,-$ & $52.066,-$ & $-6.577,-$ & $22.745,-$ & $7.461,-$ & & $-205,-$ \\
\hline & $\begin{array}{l}\text { TMS 17, BOBI FRS, } \\
\text { VUK }\end{array}$ & & & $0,-$ & & & $30.000,-$ & \\
\hline \multirow[b]{2}{*}{2022} & TFRS 16 & $22.745,-$ & $27.273,-$ & $-4.528,-$ & $22.745,-$ & $5.207,-$ & & $2.049,-$ \\
\hline & $\begin{array}{l}\text { TMS 17, BOBi FRS, } \\
\text { VUK }\end{array}$ & & & $0,-$ & & & $30.000,-$ & \\
\hline \multirow[b]{2}{*}{2023} & TFRS 16 & & & $0,-$ & $22.745,-$ & $2.727,-$ & & $4.528,-$ \\
\hline & $\begin{array}{l}\text { TMS } 17, \text { BOBI FRS, } \\
\text { VUK }\end{array}$ & & & $0,-$ & & & $30.000,-$ & \\
\hline
\end{tabular}

\section{SONUÇ VEÖNERILER}

TFRS 16 Kiralamalar Standardı ile birlikte kiracı açısından finansal kiralama ve faaliyet kiralaması ayrımı ortadan kaldırılmıştır. Kiraya veren açısından ise bu ayrıma devam edilmektedir. Kiracı işletmeler açısından tek tip kiralama modelinin öngörülmesi, bu tür işletmelerin varlık ve yükümlülüklerinin gerçeğe uygun olarak sunulmasında ve finansal tabloların karşılaştırılabilirliğinin artırılmasında önemli etkiye sahip olması beklenmektedir. Ayrıca bu duruma bağlı olarak kiracı işletmelerin finansal durum tablosu, kapsamlı gelir tablosu ve nakit akış tablosunda önemli değişimlerin de olması kaçınılmazdır. Bu bağlamda kiracı işletmelerin varlık ve borçlarında artış; buna bağlı olarak da kira giderinde azalışa karşılık finansman giderleri, faaliyet karı ve faiz, amortisman ve vergi öncesi kar düzeyinde artış olması beklenmektedir. Belirtilen kalemlerde meydana gelen değişikliklerin, işletmelerin finansal kaldıraç oranlarını, öz sermaye oranlarını, net kâr marjlarını, öz sermaye kârlılıklarını, faaliyet kârlarını, faiz karşılama oranlarını etkilemesi muhtemeldir. Nitekim söz konusu hususlar literatürde (Akdoğan ve Doğan, 2020; Yalçın, 2019; Akbulut, 2018; Acar, Temiz ve Aktaş, 2017; Akbulut, 2017; Aktaş vd., 2017; Serçemeli ve Öztürk, 2016; Öztürk, 2016; Öztürk ve Serçemeli, 2016; Sarı, Altıntaş ve Taş, 2016; Duke, Hsieh ve Su, 2009; Beattie, Edwards ve Goodacre, 1998; I mhoff, Lipe ve Wright, 1997, 1991) de ortaya konulmuştur.

\section{KAYNAKÇA}

Acar, M., Temiz, H. ve Aktaş, R. (2017). UMS 17 kiralama işlemleri standardından UFRS 16’ya geçişin finansal tablolar üzerinde etkisi: Borsa İstanbul örneği, Muhasebe Bilim Dünyası Dergisi, 19(3), 592-623.

Akbulut, D. H. (2017). Faaliyet kiralaması işlemlerinin aktifleştirilmesinin finansal tablolara ve finansal oranlara etkisinin Borsa İstanbul şirketleri üzerinde incelenmesi, Muhasebe Bilim Dünyası Dergisi, 19(2), 456-478.

Akbulut, D. H. (2018). Faaliyet kiralaması işlemlerinin aktifleştirilmesinin finansal tablolara ve finansal oranlara etkisi üzerine bir telekomunikasyon şirketinin vak'a incelemesi. Muhasebe ve Finansman Dergisi, 78, 17-36.

Akdoğan, H. N. (2019). UFRS 16 no'lu kiralama işlemleri standardının, UMS 17 no'lu finansal kiralama standardı ile karşılaştırılması, getirdiğ yenilikler ve türkiye' deki halka açık perakende şirketlerinin finansal durumlarına etkisi üzerine örnek uygulama (Yayımlanmamış doktora tezi). Başkent Üniversitesi Sosyal Bilimler Enstitüsü. 
Akdoğan, N., Aktaş, R., Deran, A., Erhan, D. U. ve Acar, V. (2011). Türkiye muhasebe standartları ile uyumlu sektörel muhasebe. Ankara: Gazikitabevi.

Akdoğan, H. N. ve Doğan, D. U. (2020). TFRS 16 kiralamalar standardının finansal tablolar üzerine etkisi ve perakendecilik sektörü üzerine bir araştırma. Muhasebe Bilim Dünyası Dergisi, 22(1), 164-191.

Aksoy Hazır, Ç. (2018). Kiralama işlemlerinin tfrs 16'ya göre muhasebeleştirilmesi ve ölçülmesi. Mali Çözüm Dergisi, 149, 85-122.

Aktaş, R., Karğın, S. ve Demirel Arıcı, N. (2017). Yeni kiralamalar standardı UFRS 16' nın getirdiği yenilikler ve işletmelerin finansal tablolarına ve finansal oranlarına olası etkilerinin değerlendirilmesi. İşletme Araştırmaları Dergisi, 9(4), 858-881.

Aslan, Ü. (2018). UFRS 16 kiralamalar standardı kapsamında faaliyet kiralamasının kiracı işletme tarafından muha sebeleştirilmesi ve raporlanması. Muhasebe ve Finansman Dergisi, 77, 55-68.

Beattie, V., Edwards, K. ve Goodacre, A. (1998). The impact of constructive operating lease capitalisation on key accounting ratios. Accounting and Business Research, 28(4), 233-254.

Cengiz, S. (2017). Finansal kiralama işlemlerinin mevzuat boyutu ve muhasebe uygulamaları: TMS 17 ve VUK kapsamında incelenmesi, Küresel Iktisat ve İşletme Çalışmaları Dergisi, 6(11), 43-56.

Demirci, Ş. D. ve Kıymaz Kıvrak, M. (2018). Ulusal ve uluslararası düzenlemeler çerçevesinde finansal kiralama işlemlerinin muhasebeleştirilmesi. Muhasebe ve Vergi Uygulamaları Dergisi, Nisan 2018 Özel Sayı, 508-531.

Duke, J. C., Hsieh, S. J. ve Su, Y. (2009). Operating and synthetic leases: exploiting financial benefits in the post-enron era. Advances in Accounting, incorporating Advances in International Accounting. 25, 28-39.

Gökgöz, A. (2019). TFRS 16 kiralamalar standardı çerçevesinde kiralama işlemlerinin muhasebeleştirilmesi. Journal of Accounting, Finance and Auditing Studies, 5(1), 318-332.

Gönen, S. ve Akça, N. (2014). Finansal kiralama işlemlerinin TMS-17 kiralama işlemleri standardı ve vergi usul kanunu açısından muhasebeleştirilmesi. Muhasebe ve Finansman Dergisi, 64, 71-94.

Imhoff, E. A., Lipe, R. C. ve Wright, D. W. (1997). Operating leases: Income effects of constructive capitalization. Accounting Horizons, 11(2), 12-32.

Imhoff, E. A., Lipe, R. C. ve Wright, D. W. (1991). Operating leases: Impact of constructive capitalization. . Accounting Horizons, 5(1), 51-63.

Kamu Gözetimi Muhasebe ve Denetim Standartları Kurumu (KGK) (2019). Finansal tablo örnekleri ve kullanım rehberi erişim adresi https://www.kgk.gov.tr/Portalv2Uploads/files/Duyurular/v2/TMS/KGK\%20Tablo\%20Formatlar\%C4\%B1\%20-\%2031_05_2019.docx

Kamu Gözetimi Muhasebe ve Denetim Standartları Kurumu (KGK) (2019). TFRS 16 kiralama standardı Erişim adres https://www.kgk.gov.tr/Portalv2Uploads/files/Duyurular/v2/TFRS/TFRS_2020/TFRS\%2016.pdf.

Kamu Gözetimi Muhasebe ve Denetim Standartları Kurumu (KGK) (2017). Büyük ve orta boy işletmeler için finansal raporlama standardı Erişim adresi https://www.kgk.gov.tr/Portalv2Uploads/files/PDF\%20linkleri/bobi_frs.PDF.

Kamu Gözetimi Muhasebe ve Denetim Standartları Kurumu (KGK) (2009). TMS 17 kiralama işlemleri standardı Erişim adresi https://kgk.gov.tr/Portalv2Uploads/files/DynamicContentFiles/T\%C3\%BCrkiye\%20Muhasebe\%20Standartlar\%C4\%B1/TMSTFRS2011Seti/T MS17.pdf.

Marşap, B. ve Yanık, S. (2018). IFRS 16 kapsamında kiralama işlemlerinin finansal raporlamaya etkisinin incelenmesi. Muhasebe ve Finansman Dergisi, 80, 23-42.

Muhasebe Sistemi Uygulama Genel Tebliği (2003). 11 Sıra no'lu muhasebe sistemi uygulama genel tebliği Erişim adresi https://www.ismmmo.org.tr/Mevzuat/11-Seri-No-lu-Muhasebe-Sistemi-Uygulama-Genel-Tebligi-31-07-2003---4071.

Örten, R., Kaval, H. ve Karapınar, A. (2019). Türkiye muhasebe - finansal raporlama standartları uygulama ve yorumları 2019 TMS - TFRS (12. Baskı). Ankara: Gazikitabevi.

Öztaş, S. ve Burak, E. (2014). Türkiye' de faaliyet kiralaması (operasyonel leasing). Kırklareli Üniversitesi İktisadi ve İdari Bilimler Fakültesi Dergisi, 3(1), 50-63

Öztürk, C. (2016). UFRS 16 kiralama işlemleri standardının eski UMS 17 standardı ile karşılaştırılması ve almanya ve Türkiye'de hisse senetleri halka açık olan hava yolu şirketlerinin finansal durumuna etkisi. Muhasebe Bilim Dünyası Dergisi, 18(1), 1-50.

Öztürk, M. ve Serçemeli, M. (2016). Impact of new standard "IFRS 16 leases" on statement of financial position and key ratios: a case study on an airline company in turkey. Business and Economics Research Journal, 7(4), 143-157.

Pamukçu, F. ve Çakmak, M. (2017). Uluslararası ticarette finansal kiralama işlemleri ve muhasebeleştirilmesi. Marmara Üniversitesi Öneri Dergisi, 12(48), 245-267.

Sarı, E. S., Altıntaş, T. ve Taş, N. (2016). The effect of the ifrs 16: constructive capitalization of operating leases in the turkish retailing sector . Journal of Business, Economics and Finance (JBEF), 5(1), 138-147. 
Sipahi, B. (2004). Leasing işlemleri ve muhasebesi, İstanbul: Türkmen Kitabevi.

Şeker, K. ve Çemberlitaş, İ. (2018). TMS 17 kapsamında finansal kiralama işlemlerinin raporlanması. Sosyal Bilimler Akademi Dergisi, 1(1), $42-60$

Serçemeli, M. ve Öztürk, M. (2016). Yeni finansal raporlama standardı “IFRS 16 kiralama işlemleri”nin getirdiği değişimler üzerine bir değerlendirme. Mali Çözüm Dergisi, 135, 31-48.

Şentürk, F. (2016). Türk vergi mevzuatı kapsamında faaliyet kiralaması yapan işletmelerde muhasebe uygulamaları. İşletme Araştırmaları Dergisi, 8(1), 619-639.

Vergi Usul Kanunu (2003). Mükerrer madde 290 Erişim adresi https://www.mevzuat.gov.tr/MevzuatMetin/1.4.213.pdf.

Yalçın, S. (2019). Muhasebe mevzuatı ve standartlarında kiralama işlemleri: muhasebeleştirme, ölçüm, sunum ve açıklamalar. Elektronik Sosyal Bilimler Dergisi. 18(72), 1619-1641. 